\title{
SEMIÁRIDO, SECA E “GERAIS” DO NORTE DE MINAS: uma revisão da bibliografia sobre o Alto-Médio São Francisco
}

\section{SEMIARID, DRY AND "GERAIS" NORTH OF MINAS GERAIS: a review of the bibliography on the High-Middle São Francisco}

\begin{abstract}
Gildarly Costa da Cruz Universidade Federal de Minas Gerais, Instituto de Ciências Agrárias, Mestrado em Sociedade Ambiente e Território. Montes Claros, MG, Brasil gc.cruz@hotmail.com

Eduardo Magalhães Ribeiro Universidade Federal de Minas Gerais, Instituto de Ciências Agrárias. Montes Claros, MG, Brasil. eduardoribeiromacuni@gmail.com

Flávia Maria Galizoni Universidade Federal de Minas Gerais, Instituto de Ciências Agrárias. Montes Claros, MG, Brasil. flaviagalizoni@yahoo.com.br
\end{abstract}

\section{Resumo}

Este artigo tem o objetivo de descrever, através de revisão bibliográfica, as características e singularidades da região denominada como "gerais", polarizada pelo município de Januária, situada na margem esquerda do Alto Médio rio São Francisco, no semiárido de Minas Gerais. Este texto caracterizou primeiramente o Semiárido brasileiro e os conflitos relacionados à concentração de terra, em seguida descreveu os gerais e especificou esse agroambiente - o processo de ocupação, os regimes agrários, a convivência com a seca. O artigo analisa como este cenário foi modificado a partir da década de 1970 com a tomada de terras e a modernização da agricultura, afetando a relação das famílias rurais com o ecossistema, afetando sobretudo o acesso à água. Como resultados, percebeu-se que transformaram-se as condições de produção das famílias rurais, que viviam intensa e fluida dinâmica de relação com a natureza. Não eram apenas lavradores da mata, dos gerais, vazanteiros ou pecuaristas familiares; ao contrário, combinavam técnicas adaptadas para produzir alimentos baseadas no uso de um amplo conjunto de conhecimentos dos recursos da natureza.

Palavras chave: Semiárido. Gerais. Seca. Rio São Francisco. Agricultura familiar.

\begin{abstract}
This article aims to describe, through a literature review, the characteristics and uniqueness of the region known as "gerais", polarized by the municipality of Januária, located on the left bank of the Upper Middle São Francisco River, in the semiarid of Minas Gerais. This text first characterizes the Brazilian semi-arid region and the conflicts related to land concentration, then describes the gerais and specified this agrienvironment - the occupation process, agrarian regimes, coexistence with the drought. The article analyzes how this scenario was modified from the 1970s onwards with land
\end{abstract}


appropriation and the modernization of agriculture, affecting the relationship between rural families and the ecosystem, especially affecting access to water. As a result, it was noticed that the production conditions of rural families, who lived intense and fluid dynamics of relationship with nature, were transformed. They were not only farmers in the forest, gerais, vazanteiros or ranchers; on the contrary, they combined techniques adapted to produce food based on the use of a wide range of knowledge of nature's resources.

Keywords: Semiarid. "Gerais". Dry. São Francisco river. Family farming.

\section{Introdução}

As regiões semiáridas do planeta apresentam precipitação média anual entre 80 a 250 milímetros. No Semiárido do Brasil é diferente: o índice pluviométrico anual costuma ficar na média entre 200 a 800 milímetros, tornando-o o semiárido mais chuvoso do planeta. Apesar disso, há uma distribuição desigual das chuvas em relação ao tempo e ao espaço, pois as precipitações geralmente são concentradas em certos períodos e lugares, distribuídas irregularmente, o que amplifica o efeito da escassez de chuva, prolongando as consequências da estiagem, intensificando a seca. Ademais, o índice de evaporação no Semiárido brasileiro é de $3.000 \mathrm{~mm} / \mathrm{ano}$, ou seja, há um déficit hídrico três vezes maior que a precipitação. Existem ainda ações antrópicas que degradam o ambiente, reduzindo a capacidade de infiltração da água no solo, provocando aumento do escoamento superficial e lixiviação, diminuindo a capacidade de recarga das fontes d'água, tornandoas impróprias para consumo humano pelo excesso de sais. Estes eventos variam entre as regiões do Semiárido, mas são importantes para compreender o curso da seca, e consequentemente as ações necessárias para o convívio com a seca e as intervenções adotadas para mitigar os efeitos da falta de água ${ }^{1}$.

No Semiárido brasileiro está situada parte dos "gerais" - chapadões arenosos, cobertos pela vegetação de cerrado, com presença de muitos corpos d'água - que ocupam quase toda a margem esquerda do Alto-Médio rio São Francisco, no extremo norte de Minas Gerais. Esses gerais foram ocupados desde o século XVIII por pequenos produtores que migraram para o Brasil interior pela via do rio São Francisco e se estabeleceram nesta combinação específica de solo, vegetação e clima, criando sistemas produtivos adaptados e peculiares. Pela profusa dotação de recursos naturais, os gerais foram considerados por viajantes, pesquisadores e formuladores de políticas como terra 
de futuro; foram pesquisados por Saint-Hilaire, Burton, Gardner, Teodoro Sampaio, Spix e Martius, Eschwege e Carlos Lacerda, que deixaram registros dessa porção do território de Minas Gerais.

Baixa precipitação, altas temperaturas e regimes de chuvas irregulares são características marcantes dos gerais norte mineiros, que registraram secas frequentes ao longo da história. Principalmente para as populações rurais, as secas tenderam a se agravar com a degradação ambiental que veio em consequência da "modernização" agrícola acelerada a partir dos anos 1970, que afetou diretamente os corpos d'água e as áreas de recarga hídrica.

As comunidades rurais dos gerais têm um modo de vida baseado na interação ativa com os ecossistemas. Essas comunidades estão situadas em áreas com agroambientes distintos, demarcados por variações de solo, disponibilidade de água e porte de vegetação. A população rural diferenciou estes agroambientes e estabeleceu classificações próprias da paisagem: áreas de gerais, mata, vazante e veredas, com potenciais, usos e domínios distintos. Essa relação peculiar com o meio originou diferentes regimes agrários, próprios da região.

O objetivo deste artigo é sistematizar informações bibliográficas sobre o semiárido, as secas e os gerais do Norte de Minas Gerais, executando uma revisão que contemple o histórico e as peculiaridades desta região. Esta revisão compreende primeiramente o Semiárido brasileiro e suas características; em seguida descreve os gerais, e especifica as peculiaridades deste agroambiente à margem esquerda do rio São Francisco, a ocupação colonizadora, os regimes agrários, a convivência com os períodos de seca e como este cenário mudou a partir da década de 1970 com a modernização da agricultura, que afetou a relação da população rural com o ecossistema. Surgiram questões relacionadas ao acesso à água, que deram origem a ações estatais e da sociedade civil para a regularização do abastecimento.

A técnica usada para elaborar este artigo foi o levantamento bibliográfico sistemático para explicar o quadro histórico e socioeconômico que informasse as relações entre população e água, a dinâmica da água no Semiárido e os seus diferentes usos produtivos; isso se relaciona com mandonismo, programas públicos e transformações produtivas nos gerais. Para isso recorreu-se a autores clássicos que analisaram história e ambiente do Semiárido, que investigaram as consequências das secas e a dinâmica 
camponesa; enfim, autores que abordaram esses temas a partir de diferentes perspectivas, mas que têm o Semiárido como tema central. A compreensão da relação entre população e recursos naturais foi essencial para entender a situação crítica das comunidades rurais em relação a secas periódicas e entender como as famílias superam esses desafios. Do mesmo modo, iniciativas estatais e da sociedade civil para regularizar o acesso à água foram pesquisadas para informar o quadro teórico e metodológico que lastreia este artigo: fundamentam uma visão das peculiaridades do Semiárido que se manifestam de forma específica em cada lugar onde há variação dos arranjos econômicos, políticos e produtivos.

\section{Resultados}

\section{Caracterização do Semiárido brasileiro}

Roberto Marinho da Silva (2006, p.15) resumiu assim o Semiárido: "as regiões semiáridas são caracterizadas pela aridez do clima, pela deficiência hídrica com imprevisibilidade das precipitações pluviométricas e pela presença de solos pobres em matéria orgânica". De acordo com a normatização do Ministério da Integração Nacional de 07/05/2018, o Semiárido brasileiro tem 1,03 milhões de quilômetros quadrados e reúne 1.262 municípios dos estados de Alagoas, Bahia, Ceará, Minas Gerais, Paraíba, Pernambuco, Piauí, Rio Grande do Norte e Sergipe, com uma população de 27 milhões de habitantes, ocupando aproximadamente $12 \%$ do território nacional ${ }^{2}$.

Segundo a Superintendência do Desenvolvimento do Nordeste (SUDENE), (Resolução nº 107/2017), a delimitação da sua área de atuação no Semiárido é definida a partir de três critérios: regiões com precipitação média anual igual ou inferior a $800 \mathrm{~mm}$, índice de aridez de Thorntwaite (razão entre a precipitação e as perdas de água pela evapotranspiração potencial) igual ou inferior a 0,50 , e por último o risco de ocorrência de seca, considerando o percentual diário de déficit hídrico igual ou superior a $60 \% \mathrm{em}$ relação a todos os dias do ano.

O Semiárido brasileiro é considerado chuvoso, com precipitação pluviométrica média anual de 200 a 800 milímetros. Porém, as chuvas são irregulares e concentradas em poucos meses do ano, e as secas que ocorrem não são apenas oriundas da escassez de 
chuvas, mas também derivadas da distribuição irregular, da concentração e das elevadas taxas de evapotranspiração aliadas a fatores antrópicos e socioeconômicos (MALVEZZI, 2007). É caracterizado ainda por temperaturas médias anuais entre 23 a $28^{\circ} \mathrm{C}$, baixa umidade relativa do ar e solos rasos, pedregosos e arenosos, ricos em minerais provenientes do intemperismo das rochas, mas pobres em matéria orgânica. Segundo Malvezzi (2007, p.9), "o subsolo do semiárido é formado em $70 \%$ por rochas cristalinas, rasas", prejudicando a formação de cursos d'água e dando características salobras às águas devido à quantidade de sais dissolvidos. Pelas peculiaridades ambientais e, sobretudo, sociais, Malvezzi definiu o Semiárido brasileiro como um "processo social”, que vai além de clima, vegetação e seca, compreendendo também laços sociais, culturais e políticos, que não podem ser estabelecidos num espaço qualquer, visto que as características ambientais tiveram significativa importância no seu processo social, e essas características permanecem associadas historicamente: seca, fome, migração, conflitos, latifúndios, por exemplo.

Euclides da Cunha foi um autor emblemático por ter revelado ao Brasil as características do Semiárido em "Os Sertões", num tempo em que não eram usados os conceitos de "Semiárido" e "Nordeste". O autor descreveu o sofrimento do "sertanejo" com a seca, numa natureza considerada "inóspita", por conta de "um contraste explicável (...) em que prevalece a intercadência de dias esbraseados e noites frigidíssimas, agravando todas as angústias dos martirizados sertanejos" (CUNHA, 1984, p. 15). Mas Euclides da Cunha também, contraditoriamente, retratou a força do "sertanejo" para enfrentar a adversidade, da qual deixou descrição memorável. Embora o clima tivesse forte influência na vida diária, e o habitante fosse aparentemente franzino e fraco:

(...) toda esta aparência de cansaço ilude. Nada é mais surpreendedor do que vê-la desaparecer de improviso. Naquela organização combalida operam-se, em segundos, transmutações completas. Basta o aparecimento de qualquer incidente exigindo-lhe o desencadear das energias adormecidas. O homem transfigura-se. Empertiga-se, estadeando novos relevos, novas linhas na estatura e no gesto; e a cabeça firma-se-lhe, alta, sobre os ombros possantes aclarada pelo olhar desassombrado e forte; e corrigem-se-lhe, prestes, numa descarga nervosa instantânea, todos os efeitos do relaxamento habitual dos órgãos; e da figura vulgar do tabaréu canhestro reponta, inesperadamente, o aspecto dominador de um titã acobreado e potente, num desdobramento surpreendente de força e agilidade extraordinárias. (CUNHA, 1984, p.51). 
A natureza e, principalmente, a seca, tornavam difíceis, de acordo com Euclides da Cunha, a vida no Semiárido. Essa associação entre Semiárido e dificuldades materiais tornou-se hegemônica no imaginário brasileiro. Foi o geógrafo Manoel Correia de Andrade (1980) quem relativizou essa ideia: para ele, o Semiárido é diverso, não é só seca. Andrade mostrou as especificidades dos lugares, estabelecendo que a seca é frequente, mas que não se manifesta em todo o Semiárido, nem tem sempre os mesmos efeitos, existindo áreas bem servidas por cursos d'água e brejos, que eram imunes às variações de chuvas. O Semiárido, assim, apresentava diversidade e características específicas, tanto em clima, quanto em solos, quanto vegetação e estruturas agrárias. Algumas áreas situadas neste clima apresentam precipitações pluviométricas anuais elevadas, outras dispõem de cursos d'água regulares com vegetação exuberante nas suas margens, frequentemente fertilizadas pela matéria orgânica que advém das encostas dos morros e chapadas durante as chuvas.

Mas, em geral, nas áreas interiores do Semiárido os índices pluviométricos dificilmente ultrapassam $800 \mathrm{~mm}$, e a vegetação apresenta caducidade das folhas, sendo denominada como "mata seca", "mata branca" ou cinzenta, caracterizando o bioma brasileiro que é a Caatinga. Nessa área em que a seca se manifesta com maior frequência, o rio São Francisco é responsável por fertilizar ilhas e áreas próximas às margens através do depósito das terras de aluvião, proporcionando assim, a agricultura de vazante para os ribeirinhos (COELHO, 2005).

\section{Mandonismo e violência no Semiárido}

Associar Semiárido a pobreza é, às vezes, uma forma de evitar tratar da concentração de terra. Conflitos por terra sempre existiram no Semiárido brasileiro. José de Souza Martins (1981), relatou essas lutas, revelando que camponeses ligados à terra por várias gerações viram-se repetidamente ameaçados ou expulsos, frequentemente submetidos a violência (MARTINS 1981, p11). Segundo Martins, o poder do latifúndio sobre a terra, exercido desde a colonização, prevaleceu sobre os direitos de lavradores; isso gerou revoltas como Canudos, Caldeirão e o fenômeno do cangaço. Foi nessa linha de argumentação que Rui Facó (1963) retratou o cangaço como contestação, luta camponesa por autonomia e liberdade, contestando o mando do latifúndio numa 
existência pautada pela exploração do trabalhador. Facó (1963, p.13), analisou as mazelas e a exploração sofrida pela população do Semiárido desde os tempos da colonização, com a distribuição de sesmarias "o domínio imperialista em ramos básicos da economia do País, um dos dois grandes obstáculos ao nosso pleno desenvolvimento econômico, social, político e cultural”. Conforme este autor:

(...) a base fundamental, a matriz do cangaceiro e do jagunço permanecia intocada: o monopólio da terra, onde o trabalhador vivia com o um semi-servo. O latifúndio produzia o mal e o alimentava. Provocava a miséria entre os despossuídos, em cujo seio nasciam os bandoleiros, que se voltavam contra o latifúndio, ainda que de maneira inconsciente. (FACÓ, 1963, p.173).

Facó criticou aos vários autores que não pesquisavam os verdadeiros problemas no Semiárido brasileiro, mas que recorriam a argumentos preconceituosos, à mestiçagem e outros argumentos duvidosos, deixando de lado questões vitais relacionadas a política, economia e sociedade. Para este autor a fome e a miséria causadas pela seca foram responsáveis pelo cangaço, que prosperou graças à omissão e ineficiência dos governos.

Frederico Pernambucano de Mello (1985) desenvolveu mais essa argumentação; entendeu que o cangaço era não somente uma forma de revolta contra o latifúndio, mas também um meio de vida que se tornava tanto mais importante nas situações de seca mais aguda. A vingança pessoal não tinha grande importância para a entrada no cangaço, os cangaceiros se profissionalizavam na vida errante de combates, pois o cangaço representava uma opção de vida, quando não havia muitas outras opções.

Como o cangaço, os conflitos: José de Souza Martins (1981), considerou que a guerra de Canudos foi um confronto de camponeses que não se sujeitavam ao controle da terra pelos latifundiários. Mesmo que grande parte dos jornais da época retratassem os combatentes de Canudos como "bandidos" por serem considerados inimigos da República, Martins (1981, p. 52), afirmou que tudo indicava ser este um movimento em demanda por justiça, que se contrapunha ao mando de classe dos coronéis.

Estes coronéis surgiram com a Guarda Nacional, substituindo as milícias do Império pela organização armada e descentralizada dos potentados locais, dando corpo ao fenômeno do "coronelismo". O coronel exercia um comando municipal ou regional, sobrepujando aqueles que dispunham de mais terras e agregados. No coronel baseava-se o mando local que surgiu no Segundo Reinado, e dominou na Primeira República 
(COELHO, 2005; QUEIRÓZ, 1976). Sobre a influência política dos coronéis no Semiárido, Martins (1981, p.46) escreveu que:

Os governadores (...) operavam dentro do mesmo esquema através de um sistema de trocas com os chefes políticos do interior, os coronéis. Esse sistema envolvia um complicado mecanismo de trocas que compreendia a nomeação de funcionários municipais indicados pelos coronéis, a designação de autoridades policiais e judiciais do mesmo modo, facilidades na concessão de terras e favores na realização de obras públicas.

Segundo Martins, o voto do eleitorado cativo era a arma do coronel para manter sua estrutura de mando e adquirir influência na política, visto que o voto era tratado como bem de troca, sendo assegurado pelo coronel em troca da fidelidade do eleitor. Mas isso não significa que os coronéis despendiam grandes somas com seu eleitorado; como retratou Martins (1981), o voto era trocado por pares de sapatos, abertura de créditos ou algum pedaço de terra. E assim, o mando no Semiárido permaneceu sob o controle dos coronéis.

O misticismo também marcou e ainda marca a vida das populações do Semiárido. Desde o começo do século XX autores como Euclides da Cunha descreveram a reza ou a fé do "sertanejo" como alternativa para amenizar as agruras das secas. Coelho (2005) percebeu que, nas condições em que se modelou a vivência da população rural do Semiárido, certas marcas culturais tornaram-se legítimas expressões desta sociedade, porém o misticismo ocultou um vasto saber tradicional transmitido entre gerações. As populações do Semiárido usam diversas formas de manifestação associadas à fé religiosa para se relacionar com a natureza: as divindades explicam serem muitos os dias com chuvas e aconteceram colheitas fartas. Assim, recursos naturais são considerados como dádivas, e a dádiva é separada da fé por uma linha tênue. É a partir da religiosidade que se sabe época de plantio, de tratos culturais e colheitas, e, por exemplo, previsões do calendário de chuvas são feitas através das crenças religiosas. Manoel Correia de Andrade (1980) e também Galizoni (2005) relatam previsões de secas relacionadas com os dias de São José e São Pedro³.

\section{Gerais}

A região Norte e o Vale do Jequitinhonha fazem parte da delimitação oficial do Semiárido de Minas Gerais. Nestas mesorregiões, com dezenas de comunidades rurais, 
as chuvas são concentradas e distribuídas irregularmente ao longo do ano, a vegetação tende à heterogeneidade pela confluência dos biomas Cerrado, Caatinga e Mata Atlântica, há chapadas extensas, planas, com vegetação rasteira de pequeno porte.

Na porção mais ao norte do Semiárido de Minas Gerais, à margem esquerda do alto-médio rio São Francisco, há uma área composta pelo encontro de Caatinga e Cerrado, que compreende também parte dos estados da Bahia e Goiás, que é denominada como "gerais" pela população do lugar (ver Figura 1). Mas essa definição pode se tornar imprecisa se não se especificar com exatidão a localização: existem "gerais" associados à Serra Geral e do Espinhaço, "gerais" associados a campos-cerrados do Sul de Minas, "gerais" associados à peculiar relação solo-vegetação-clima da bacia do rio São Francisco, "gerais" usado no gênero feminino ("as gerais") em referência aos chapadões do Sudoeste da Bahia. Estudando o norte mineiro, Gonçalves (2000) relacionou o termo “gerais” à existência de campos sem donos, usados em comum pela população; por isso, o termo seria indiferentemente usado em Minas Gerais, Paraná e Rondônia, por expressar mais condição de uso que propriamente característica natural.

Figura 1: Mapa dos gerais de Januária, no Alto Médio rio São Francisco, destacando a hidrografia.

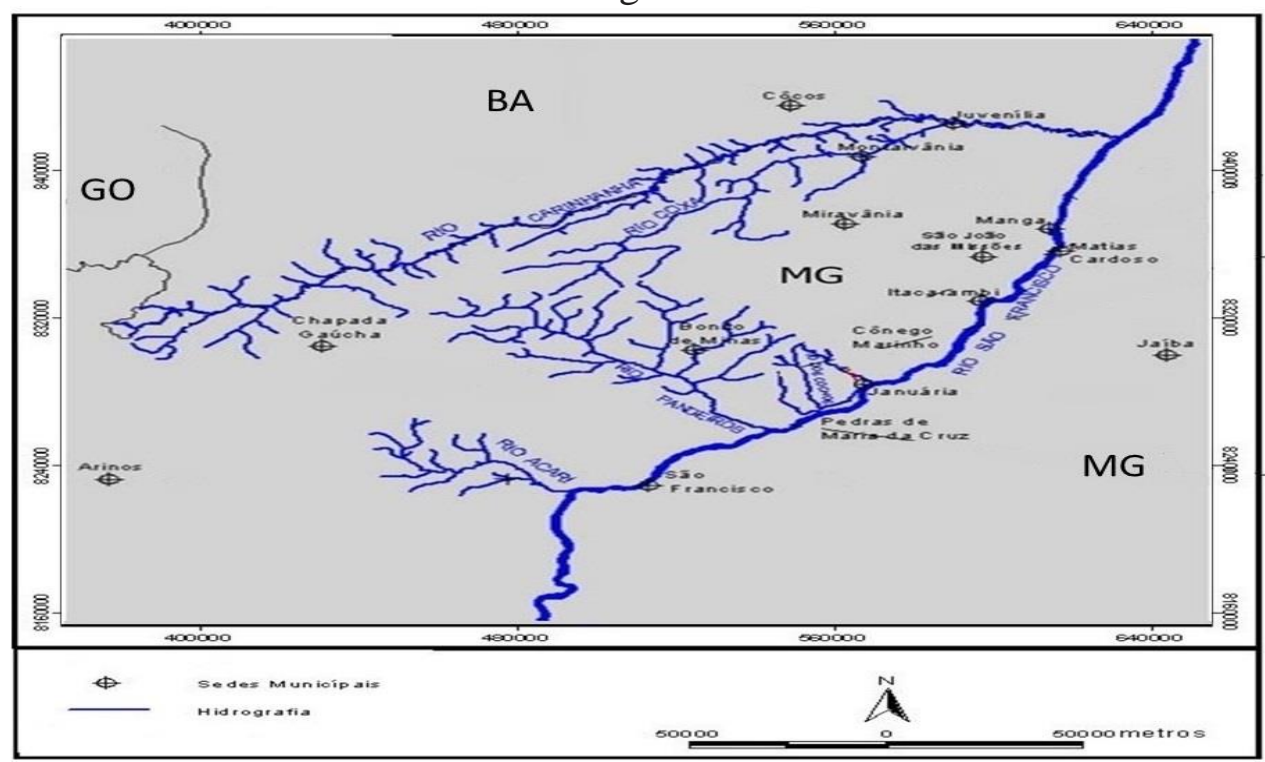

Fonte: Clemente, C.M.S. (em Ribeiro, E.M., Histórias dos gerais, Belo Horizonte, Editora UFMG, 2010). 
Os "gerais" analisados neste artigo se localizam na depressão do rio São Francisco, no Alto-Médio rio. Estes, na margem direita, ao longo da história ficaram conhecidos como "gerais de São Felipe" por conta da serra do mesmo nome; na margem esquerda a denominação varia, pois são denominados como os "gerais da Carinhanha", ou "de Januária", ou "de Pandeiros", ou "do Acari”, conforme o lugar, mas sempre designando a extensa mancha de areia quartzosa que no sentido sul-norte vai de Buritizeiro em Minas Gerais a Bom Jesus da Lapa, já na Bahia.

Estes, foram definidos assim por Ribeiro (2010):

Os gerais da margem esquerda do Alto-Médio rio São Francisco são chapadas extensas e pouco elevadas, cobertas por vegetação arbustiva e rasteira, assentados na maioria dos lugares sobre solos muito pobres e secos, formados por areia quartzosa. (RIBEIRO, 2010, p 23).

Galizoni (2005), descreveu assim os mesmos gerais, de Januária:

Gerais são terras arenosas com vegetação baixa e retorcida localizadas em chapadões (planaltos). São terrenos considerados fracos para o plantio de lavoura e identificados principalmente por vegetação baixa que, nas palavras dos agricultores: 'Mal cobre uma pessoa', composta por arbustos como cajuí, murici, cajuzinho e grão de galo, entrecortados por árvores como o pequi, cabeça de negro (araticum), pau d'olinho, folha larga, sucupira, mangaba e jatobá. (GALIZONI, 2005, p 139).

Estas caracterizações são relevantes para precisar o lugar, compreender o ambiente e o modo de vida das populações rurais, visto que as pessoas transformam este ecossistema em lugar de viver, conduzindo lavouras, pecuária e coleta de recursos florestais, operando um sistema de "conhecimento agrícola tradicional que combina os recursos naturais diferentes em unidades de exploração que devem sempre incluir gerais, brejo e terras de cultura; ou mata, gerais e vazantes" (RIBEIRO, 2010, p 25$)^{4}$.

Os gerais do Alto Médio São Francisco apresentam solos arenosos, profundos e bem drenados, ultrapassando dois metros de profundidade. Os elevados teores de areia tornam os solos propensos à erosão e lixiviação dos nutrientes, com baixo armazenamento de água e, consequentemente, pouca disponibilidade deste recurso para as plantas (SPERA et al, 1999). É por isto que o manejo mecanizado desses solos exige muitos cuidados; abertura de áreas de plantio e estradas que não levem essas características em conta, costumam ter consequências desastrosas. 
Em algumas épocas do ano o rio São Francisco tende a diminuir a vazão, seus afluentes minguam nos períodos de estiagem que coincidem com o inverno no Sudeste brasileiro. Galizoni (2005, p. 125), ressalta que "na estação seca, que é a mais extensa, os rios, córregos e riachos se recolhem, a vegetação fica pardacenta e com poucas folhas." Mas quando caem as chuvas, segundo as palavras de Euclides da Cunha (1984), ocorre uma "mutação em apoteose", em que o verde radiante toma conta da paisagem, em árvores sem uma folha sequer surgem copas formidáveis, gerando sombras capazes de abrigar uma boiada inteira.

O rio São Francisco tem papel fundamental nesses gerais. Segundo Marco Antônio Coelho (2005, p. 30), o engenheiro Teodoro Sampaio descreveu o rio como um “oásis no deserto, através dos sertões adustos da Bahia ao Ceará, de Pernambuco ao Piauí, dizendo que era a terra da promissão e o refúgio daqueles povos assolados pela seca prolongada e periódica”. E, efetivamente, o rio São Francisco é essencial para a vida de muitas populações rurais. É o seu ciclo de águas que estabelece o ritmo de vida das famílias e o seu modo de organizar a produção. Andrade (1980, p.36) revela que:

\begin{abstract}
Com as cheias, as ilhas e terras marginais submergem, sendo fertilizadas pelo rio e, à proporção que as águas baixam, são utilizadas pelos agricultores ribeirinhos para a formação de roçado; estes aproveitam o húmus depositado pela cheia, como a umidade deixada pelo rio, e novas áreas vão sendo descobertas e as culturas continuam a expandir-se, formando o que chamamos de agricultura de vazante, que garante ao sertanejo o milho, o feijão, o amendoim, a fava, a cana-de-açúcar.
\end{abstract}

Coelho (2005, p.142) considera que "não há como pensar o rio São Francisco e o cerrado sem se pensar nas veredas e nas lagoas marginais", enfatizando que há grande biodiversidade ao longo do rio. Essa diversidade é encontrada também nos gerais, pois os ambientes se interligam e são dependentes uns dos outros. Sujeitos a uso humano, são denominados por Dayrell (1998) como "agroecossistemas". As populações que habitam nestes agroecossistemas usufruem destes espaços, valorizando os potenciais de cada um com sua singularidade. Agricultores familiares dos gerais "descriminam o ambiente em três principais zonas denominadas como vazantes, matas e gerais. Cada uma dessas áreas tem especificidades variadas de solo, de vegetação e de água, além de possuírem também variações ambientais internas" (GALIZONI, 2005, p.125). 
No rio São Francisco cheias e secas explicam a agricultura de vazante, feita nas margens do rio e de seus afluentes, que além de garantir a segurança alimentar aos produtores familiares, produz mantimentos fundamentais para abastecimento das cidades ribeirinhas, que dependiam diretamente dessa produção. As vazantes são áreas frequentemente inundadas e fertilizadas pelos rios, que durante as cheias deixam restos de aluvião (areia, argila e matéria orgânica) concentrados nas margens. Com o fim do período chuvoso e início da estação das secas os agricultores familiares denominados como vazanteiros usam as margens dos rios, córregos e lagoas marginais para produção de alimentos como milho, feijão, mandioca, melancia e abóbora, usando fertilidade do solo, umidade e proximidade com o rio, para combinar agricultura com pesca (GALIZONI, 2005).

Mas a partir da década de 1950 inúmeras obras de engenharia na bacia do São Francisco prejudicaram os agricultores vazanteiros. De acordo com Coelho:

\footnotetext{
Na década de 1950, as obras realizadas na bacia (barragens e represas), trouxeram uma diminuição acentuada na agricultura de vazante. Isso porque o fluxo das águas passou a ser determinado pelas usinas hidrelétricas, causando notável redução das áreas que todos os anos eram fertilizadas pelas enchentes na estação chuvosa (nas ilhas e nas margens do rio), terras que anteriormente eram utilizadas para lavouras de ciclo curto, como as de milho, feijão e mandioca. (COELHO, 2005, p 124).
}

Assim, pode-se afirmar que os impactos causados pelas obras de engenharia na bacia do rio São Francisco tiveram efeitos não somente ambientais, mas também socioeconômicos, visto que interferiram na fertilização natural das ilhas e margens do rio, afetaram diretamente usos costumeiros e o abastecimento das cidades ribeirinhas.

Vazantes são utilizadas na época das secas. Matas, denominadas matas-secas ou caatingas, são igualmente importantes, para agricultura, pois no início do período de estiagem as árvores perdem folhas, formando uma densa camada de matéria orgânica sobre o solo. Com a passar do tempo, esta matéria é incorporada ao solo, tendo papel fundamental na sua fertilização, tornando-o propício para o plantio de diversas culturas (SANTOS et al, 2010). 
Figura 2: Paisagem dos gerais de Januária, $\mathrm{MG}$

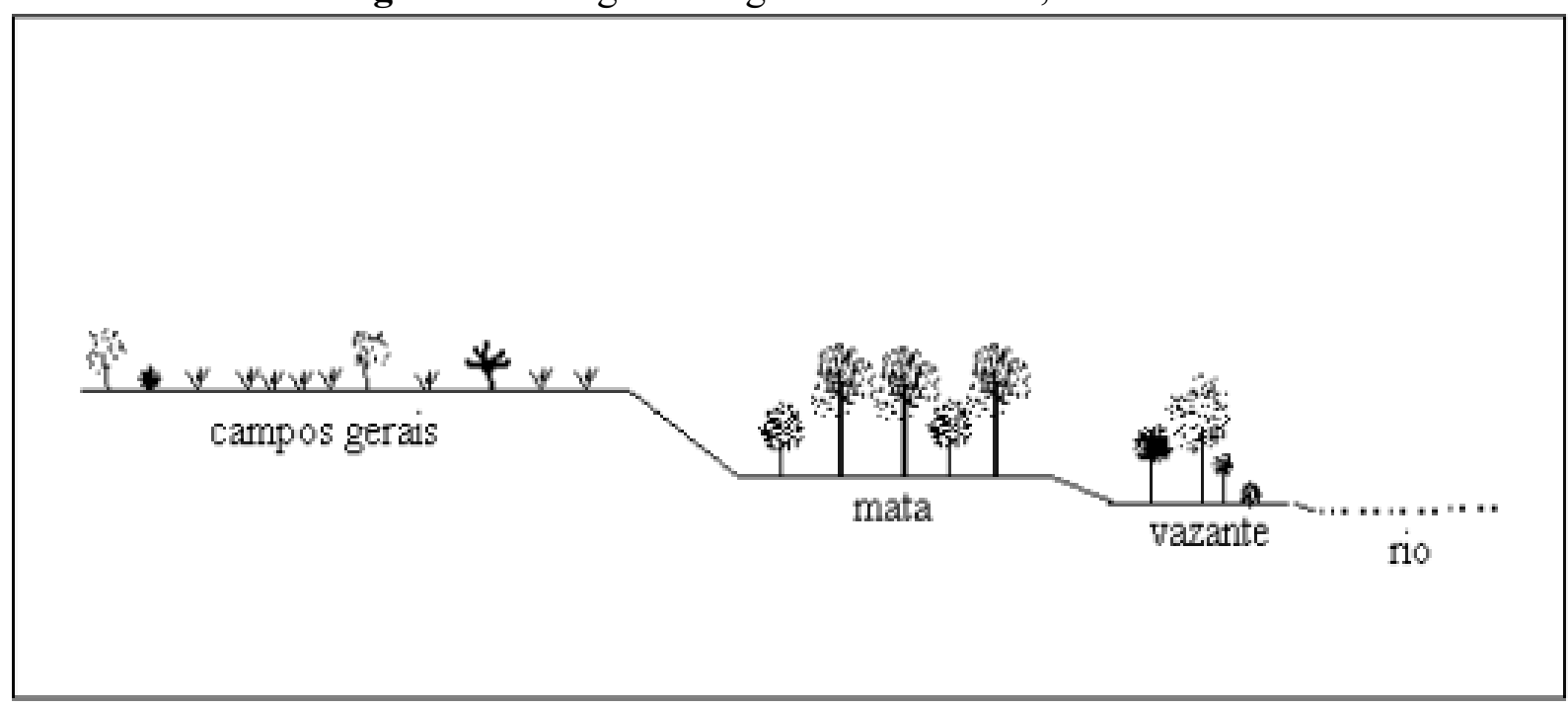

Fonte: Galizoni, 2005.

Apesar da fertilidade escassa dos solos dos gerais, isso não significa que este ambiente seja preterido pelas populações rurais; pelo contrário, Ribeiro (2010, p. 24) esclarece que "a terra fraca dos gerais oculta muitas virtudes. Os brejos são fertilíssimos, verdadeiros oásis na paisagem quase árida das chapadas, terras excelentes que produzem alimentos durante todo o ano". Neste ambiente encontram-se os cursos d'água como nascentes, veredas e brejos que, nas épocas de estiagem, são utilizados para plantio. As áreas de gerais são elevadas e as terras de matas ficam próximas às vazantes. Na parte mais baixa da paisagem fica o rio, depois as vazantes, as matas e por fim os gerais.

Certamente o fator mais importante para a vida nos gerais é a água. "As águas dos gerais são das mais reputadas, consideradas mais resistentes e as melhores para se beber: finas, leves, cristalinas, doces, frescas e sadias; qualidades percebidas pelo gosto" (GALIZONI 2005, p.140). Segundo a autora, as águas dos gerais são oriundas do olho d'água e da mãe d'água. O olho d'água é um ponto fixo do qual a água brota, formando pequenos cursos d'água; as mães d'água são áreas alagadas que aparecem quando o lençol freático alcança a superfície, formando veredas e brejos. Nos gerais as águas do olho d'água têm muita utilidade para consumo doméstico, beber e cozinhar, para a lavoura e dessedentação dos animais. Já os brejos e veredas são propícios para o plantio de alimentos durante todo o ano, são áreas férteis e úmidas, tendo importância na segurança alimentar das famílias (GALIZONI, 2005; SANTOS et al, 2010; MEDEIROS, 2011). 
As populações do rio São Francisco têm características peculiares. Antes mesmo da colonização, que começou no século XVIII, essas terras eram ocupadas por indígenas que foram exterminados, ou mais seguramente escravizados, de forma que:

(...) no transcurso de quatro séculos, no vale do São Francisco e de seus afluentes, foi criado um modo de vida com características singulares, uma vivência social peculiar que marca o extenso território que vai do Norte de Minas até os sertões do Nordeste. Fatos e acontecimentos ilustram e exprimem uma realidade que pode ser denominada de "civilização do São Francisco". (COELHO, 2005, p.47).

Durante três séculos essa população se adaptou ao vale do São Francisco, e seguiu sua própria dinâmica econômica, usando o rio como forma de sustento e meio de transporte. Cardoso (2000) informou que desde o período colonial havia resistências que dificultavam a arrecadação de impostos na margem do rio, e que as populações que viviam próximas ao São Francisco estabeleceram suas próprias conexões sociais e econômicas. Os gerais de Januária, segundo Ribeiro (2010, p.25), foram:

“das primeiras regiões de população agricultora, criadora e sedentária de Minas Gerais. Desde então o adensamento populacional só fez aumentar, animado pela produtividade agrícola e pelas redes de trocas que foram estabelecidas ao longo do rio São Francisco."

A colonização dos gerais de Januária foi marcada por confrontos entre colonizadores e indígenas caiapós, que viviam na margem esquerda do São Francisco. Joaquim Ribeiro (2001) relatou que nas últimas décadas do século XVII no Alto-Médio rio São Francisco se encontrava a aldeia de Itapiraçaba, de caiapós, que tinha contato com outros povos; estes, segundo Pereira (2004), conheciam diversas práticas e culturas agrícolas destruídas pelos colonizadores. $\mathrm{O}$ autor relatou o ataque à aldeia de Itapiraçaba:

"Pegos de surpresa, neste cerco noturno, a aldeia foi impiedosamente atacada. (...). Para a nação caiapó ribeirinha, a destruição de Itapiraçaba foi doída e, mais sentido ainda, o fato de perderem o controle do grande rio, eles que já haviam perdido o litoral para os brancos." (Pereira, 2004, p.65-66).

Itapiraçaba tornou-se a partir de então Brejo do Amparo, próximo a Porto do Salgado, que por fim se tornou a cidade de Januária, que teve forte influência econômica nas áreas ribeirinhas de Minas Gerais e Bahia, além de ponto de comércio de produtos da agricultura e pecuária da província de Goiás, com trocas de sal por gado. 
A ocupação colonizadora dos gerais do Alto-Médio rio São Francisco não seguiu o padrão agrário que se acredita ter seguido o Nordeste brasileiro ao longo deste mesmo rio. Em particular, a margem esquerda do rio São Francisco não foi marcada pelas grandes propriedades rurais; ao contrário, foi fronteira agrícola até os anos 1980 (RIBEIRO, 2010; MEDEIROS, 2011). A extensa área de gerais era terra de livre acesso, e as populações ocupavam os lugares propícios para a produção agrícola cíclica - vazantes, nascentes, veredas, brejos, cursos d'águas. A ocupação de terra próxima às fontes d'água combinava recursos naturais advindos das matas e dos chapadões de gerais, incluindo a pecuária na solta. Portanto, não era a propriedade fixa da terra e nem o seu tamanho que definia a capacidade de controle da produção agrícola, mas sim a capacidade de usar os recursos disponíveis na natureza. Assim, para compreender a ocupação colonizadora da área dos gerais, é fundamental compreender a forma como a agricultura familiar organizou a produção. $^{5}$

\section{Agricultura dos gerais}

A agricultura dos gerais foi baseada na unidade familiar de produção. Agricultores consideram que existem lugares próprios para fazer o roçado, que são determinados pela cor do solo, porte da vegetação e a presença de plantas que indicam a fertilidade do solo. O cruzamento destas observações recomenda as culturas que devem ser plantadas. Segundo agricultores é possível identificar solos pelas vegetações:

“(...) o cerrado, conhece pela textura da casca da árvore. Na terra da mata a casca da árvore é mais fina; no cerrado a casca é mais grossa. Na área de mata, você chega ao pé de uma árvore e a casca é bem fininha, você vai para o cerrado a casca da árvore já é mais grossa. A natureza é perfeita". (SANTOS et al, 2010, p.157)

A identificação da vegetação é essencial para o sucesso da lavoura.

Os solos de gerais são ácidos, profundos, porosos, pobres em matéria orgânica e fertilidade natural, principalmente em macronutrientes como nitrogênio, fósforo, potássio, cálcio e magnésio. Casca grossa das árvores e troncos tortuosos se associam à acidez do solo, que geralmente apresenta pH entre 4 e 5. Porém as raízes destas árvores são profundas, com metros de comprimento, rompendo a barreira da acidez. É como se 
fosse uma "floresta invertida", visto que a maior parte da biomassa se localiza nas raízes, de acordo com o Sistema Nacional de Informações Florestais (SNIF, 2006).

É de suma importância conhecer a vegetação para cultivar o roçado, e a probabilidade da lavoura não produzir nos gerais é maior que na área de mata. As matas têm maior fertilidade natural e quantidade de matéria orgânica em relação ao gerais, têm árvores altas e pouco espaçadas (GALIZONI, 2005). ${ }^{6}$

A pecuária nos gerais era feita nas áreas comuns, geralmente chapadas, as chamadas "soltas", em que gado pastava livremente e se alimentava de capim nativo, ramos e frutos do cerrado. O capim nativo era manejado com fogo para a renovação do pasto, pois o gado tem apreço pelo broto (SANTOS et al, 2010).

Os geralistas mantêm íntima relação com a natureza; além da terra para produção de alimentos, a coleta de frutos nativos é crucial para complementação alimentar ${ }^{7}$. Nos gerais da margem esquerda do Alto-Médio rio São Francisco o extrativismo proporcionava diversa variedade de frutos nativos como pequi, coquinho azedo, buriti, manga, cagaita, maracujá do mato, cabeça de nego, umbu, entre outros (GALIZONI, 2005). A pesca e caça também contribuiam para a variedade de alimentos. Assim, a família camponesa não sobreviveu apenas da lavoura, mas usou todo o ecossistema. Nos gerais o agroextrativismo ainda é muito importante para as famílias, pois os frutos são destinados tanto para consumo quanto para a comercialização.

As roças de toco ou coivara eram plantadas nos brejos e matas. Antes das primeiras chuvas se fazia o corte da vegetação de forma que esta pudesse brotar novamente. Plantavam as lavouras e, após a colheita, a terra era deixada para "descansar". O tempo pousio de cada área era definido de acordo com as características da vegetação, variando entre um ano nas terras de mata e até dez anos nos campos e capoeiras. Segundo os lavradores, este sistema proporcionava grandes colheitas, porque a terra ficava ociosa tempo suficiente para recuperar sua fertilidade e assim ser cultivada novamente. Solos de mata, mais férteis, admitiam pousio curto, breve "descanso" da terra após a colheita (SANTOS et al, 2010).

O conhecimento dos agricultores geralistas tem fortes influências dos seus antepassados. São práticas que foram aperfeiçoadas com o passar dos anos, adequandose às dinâmicas ou transformações que vieram a acorrer no ambiente. $\mathrm{O}$ conhecimento da natureza revela as bases de um saber tradicional e cultural, mostrando que os recursos 
disponíveis não são apenas insumos, mas bens fluídos, dádivas. Klaas Woortmann (1990, p.17) esclareceu que "a tradição (camponesa) não é o passado que sobrevive no presente, mas o passado que, no presente, constrói as possibilidades do futuro". Ou seja, a tradição é forma de sobrevivência, de superação das adversidades.

Nos gerais do Alto-Médio São Francisco, aproveitando áreas úmidas dos buritizais, agricultores costumavam "botar brejo", plantando mantimentos na estação da seca e, usando "água de regra", costumavam produzir até três safras por ano (GALIZONI, 2005; MEDEIROS, 2011). Segundo Medeiros (2011), "botar brejo” significava modificar o brejo através do trabalho que se fazia na terra. Ressalta-se que Medeiros diferencia "brejo" de "vereda", sendo a presença e função da água a principal distinção: quando a água neste agroambiente é límpida, própria para o consumo e abastecimento, denominase "vereda", quando possui grande carga de matéria orgânica é "brejo". Ainda segundo esta autora, "botar brejo" implicava também que os camponeses deviam seguir longos percursos para cultivar a lavoura em terras de uso comum, procurando áreas "novas" e desocupadas.

A agricultura de vazante também é muito importante. Inundações anuais formam ilhas, nem sempre são isoladas da terra, mas geralmente partes das margens que nos períodos de cheias ficam totalmente submersas, restando fora d'água somente algumas partes mais elevadas de terras, onde os vazanteiros constroem casas. Esses "lombos" são inundados em cheias excepcionalmente fortes. Nas vazantes às vezes crescem árvores altas, geralmente sem cerne, como pau jaú, mangue, alagadiço e jomerim; aparece também aroeira, madeira de cerne, que nasce em terras de vazantes e em terras firmes e indica terrenos férteis. As terras de vazantes são partilhadas em comum pelos vazanteiros (GALIZONI, 2005).

A lavoura nas vazantes exige conhecimento: carece conhecer o terreno e o plantio que requer, é preciso conhecer o tempo, identificar sinais de chuva e de seca; é preciso conhecer o rio e prever as cheias. Classificam o terreno de acordo com o pó que produz. Também selecionam espécies que conseguem conviver com água no pé, como é o caso da cana manteiga, que resiste à inundação. Vazanteiros consideram o milho o principal plantio, mas não consideram as abóboras plantadas. Feijão de corda é plantado junto com o milho ou com a mandioca nas áreas que não são inundadas. Esse feijão é muito resistente, adaptado às condições da região e não dispensa maiores cuidados. Algumas 
famílias costumam vender feijão de corda e cana nas feiras, mas vazanteiros plantam principalmente para seu próprio consumo. Além disso fazem hortas nas beiras das lagoas e do rio, plantando variedades de folhas, temperos e alho (GALIZONI, 2005).

Seguindo o rio, vazanteiros plantavam na estação seca do ano aproveitando a umidade. Geralmente as famílias conseguiam fazer dois plantios. Um começava ao final de fevereiro para ser colhido em junho, e outro realizado em junho, colhido em outubro. Nos três meses do período chuvoso, denominado como "inverno", as vazantes ficam inundadas pelas águas, restando emersos os pontos altos onde ficam as casas e terrenos de seu entorno onde cultivam mandioca e feijão catador.

Vazanteiros coletam água do rio para beber e outros usos. Cada família tem sua fonte no rio: ponto de captação da água, lavar roupa e tomar banho. Além da água do rio, costumam fazer cacimbas - cava rasa que na região quase sempre é feita na forma de uma rampa que adentra na terra - para ter água mais perto de casa. Escolhem o local onde fazê-las para conseguirem melhores águas. No período da seca, denominado como "verão", a água do rio tem melhor qualidade. Na época da chuva - o "inverno" -, vazanteiros são cercados por água, mas não a tem para beber porque o rio torna-se barrento, criando um dilema no que diz respeito à água: próximos do rio, mas sempre procurando água. Isto é decorrência da percepção de qualidade de água dessas famílias. A principal característica que os vazanteiros gostam na água é ser corrente, que se renova constantemente. Uma água que fica parada, não tem movimento, como as das lagoas, não consideram boa para beber (GALIZONI, 2005).

Dayrell (1998, p.10), afirmou a necessidade do reconhecimento social destas técnicas usadas por essas populações rurais, que carregam um estilo próprio, uma racionalidade produtiva que não está dissociada da natureza, pelo contrário, está intimamente ligada, pode dar pistas seguras quando se pretende promover a sustentabilidade da agricultura familiar e apontar alternativas de desenvolvimento que permitam conciliar a produção com a conservação da natureza. Essa cultura camponesa tem um modo de vida que pode evitar degradações ambientais, porque sua cultura se renova, se aprimora, é fluida e segue o princípio da convivência. 


\section{Regimes agrários}

Veredas, brejos, campos e carrascos são microambientes característicos dos gerais da margem esquerda do Alto Médio rio São Francisco. Lavradores dos gerais têm forte ligação com o ecossistema, dependeram dos brejos e veredas para produção de alimentos durante as secas; áreas de mata eram cultivadas durante o período das chuvas e vazantes quando terminam a época das cheias. Famílias geralistas dependem dos recursos da natureza, e impactos ou intervenções que venham a degradar este ambiente repercutem diretamente sobre a segurança alimentar (GALIZONI, 2005).

Historicamente os gerais apresentam secas frequentes devido às condições naturais do clima. Porém, esta situação tendeu a se agravar com a degradação ambiental acelerada a partir dos anos 1970, com a "modernização agrícola" que afetou diretamente os cursos d'água e as áreas de recarga hídrica que eram reguladas pelo costume (RIBEIRO, 2010).

Agricultores familiares dos gerais dominavam áreas que continham cursos de água e outros espaços, destinadas ao uso comum para criação de gado e extrativismo, sendo o costume o principal mecanismo de regulação do acesso aos recursos. Esses direitos comuns eram locais, delimitados geográfica, ambiental e socialmente (GALIZONI 2005, p.27).

As terras utilizadas pela população em regime comum nos gerais tinham particularidades. Combinavam e alternavam o uso dos recursos, sejam as nascentes, chapadas, veredas, brejos, vazantes ou áreas de mata. Ribeiro (2010), explicou que as terras dos gerais não eram ocupadas pelas grandes fazendas. Até os anos de 1970, antes dos gerais serem tomados pela modernização agrícola, a terra era de livre acesso, e o domínio exclusivo da família era próximo aos cursos d'água, justamente onde havia concentração da população, porque ali a produção de alimentos era abundante. Ribeiro esclareceu que as divisões de terras entre camponeses eram feitas na perpendicular, com demarcações até determinada altura, quando atingissem a divisa de terras de cultura ou de capões com os gerais. Depois de feitas essas demarcações de terra até a área limite, adiante poderia ser domínio de uma família, mas não se delimitava: ficava no comum, ou seja, no uso coletivo. Portanto o domínio da terra se limitava, sobretudo, com o acesso a água. Joaquim Viana (2010), relatou que seu terreno tinha 30 metros de frente na beira 
d'água e 2.000 metros de fundo na direção dos gerais. Os terrenos dos gerais são estreitos de frente e compridos de fundo exatamente para que as famílias não fiquem sem acesso a água. Já as nascentes e veredas não faziam parte das divisões de terra, eram áreas de responsabilidade coletiva, porque essas fontes de água originavam córregos e rios. Característica peculiar do regime fundiário dos gerais é a "fazenda geral". 8 Fazendas gerais são grandes áreas, abrangendo várias comunidades rurais, fazendas e sítios que fazem parte de uma única gleba originária. Os gerais eram divididos em várias fazendas gerais, e as pessoas assim se identificavam: “-Sou Fulano, da comunidade tal, fazenda geral tal” (RIBEIRO 2010).

Existiam "soltas", áreas extensas nas quais o gado podia pastar à vontade, chegando a se distanciar vários quilômetros do terreno do criador. Quando o gado era solto nessas áreas de gerais, apenas algumas vacas leiteiras ficavam perto das residências para produzir leite. Para a renovação do pasto era utilizada a técnica da queimada, geralmente a cada dois ou três anos, antes do período das chuvas. O fogo transformava o pasto antigo em cinzas que serviriam de adubo e correção da acidez para o solo; o broto novo do capim se tornava também mais palatável, sendo preferido pelo gado (GALIZONI, 2005; RIBEIRO, 2010; MEDEIROS, 2011; SANTOS et al, 2010).

Galizoni (2005, p.143) afirma que duas áreas dos gerais eram fundamentais para a população local: "as cabeceiras d'água e as soltas, para extração e criação de gado". Soltas eram manejadas com fogo, mas fogo era considerado uma técnica destinada a melhorar o pasto, fazendo com que esse brotasse e servisse de alimento para o gado. Ribeiro (2010, p.28), constatou que:

\footnotetext{
"sem o fogo a cada dois anos, com o chão recoberto de folhas, a chapada ficaria sujeita a incêndios que destruíram definitivamente parte da vegetação, atrasariam a frutificação das plantas nativas que, então, forneciam pouco alimento para o gado no próximo ano".
}

Geralistas diferenciavam fogo e incêndio; os incêndios são descontrolados e na maioria das vezes não são planejados. A técnica de fogo nos gerais era utilizada quando a vegetação não estava densa, geralmente no período em que a incidência dos ventos e insolação não espalhavam as chamas. Eram feitos também aceiros, evitando o contato das chamas com outras áreas. Segundo Medeiros (2011), renovar as pastagens era essencial 
para evitar as grandes queimadas, pois o capim seco e alto produz significativa quantidade de biomassa que queima muito, causando grandes prejuízos a flora e fauna.

O fogo não era utilizado em todos os microambientes dos gerais pois os geralistas sabiam que em alguns lugares a vegetação não o suportaria. Galizoni (2005), relata que os agricultores sabiam que nas áreas de capões e matas as árvores têm raízes rasas, e os agricultores acreditavam que não suportariam o fogo; já as áreas de gerais as árvores têm raízes profundas, até mesmo maiores do que a árvore. Os gerais são resilientes ao fogo, têm capacidade de se restabelecer de impactos ou distúrbios, o ecossistema é perfeitamente capaz de ressurgir após as queimadas.

\section{Modernização dos gerais}

A política de modernização agrícola para o Norte de Minas, apoiada pelo Estado nos anos 1970, seguiu quatro eixos básicos: “(a) reflorestamento de eucaliptos e pinhos em diversos municípios da região; (b) implantação de grandes projetos agropecuários; (c) instalação de indústrias em poucos municípios; e, (d) implantação de perímetros de agricultura irrigada, também de forma concentrada" (RODRIGUES 2000, p. 107). Esses programas se disseminaram por toda região: o município de Montes Claros foi recebeu diversas indústrias e forte impulso de compras de terras por investidores de municípios do sul; o maior projeto de perímetro irrigado da América Latina foi implantado às margens do rio São Francisco; em Januária foram implantados projetos de reflorestamento, agropecuários e agricultura irrigada na bacia do rio Pandeiros. Esses projetos afetaram as relações tradicionais de domínio da terra, instituíram novas relações entre proprietários de terra e trabalhadores rurais (GERVAISE, 1975; GONÇALVES, 2000).

Os agroambientes dos gerais da margem esquerda do Alto-Médio rio São Francisco também se transformaram, com a instalação de "firmas" em chapadas, veredas, brejos, nascentes, rios, córregos, matas e vazantes. Ribeiro (2010), ressalta que chapadas foram destinadas a criação intensiva de gado, reflorestamento e carvoejamento; veredas e brejais foram drenados e sistematizados para a produção de grãos; a mata seca foi transformada em carvão e, posteriormente, em áreas de pasto. 
Estas circunstâncias tiveram impactos significativos nas populações dos gerais, afetando o seu modo peculiar de convivência com a natureza ${ }^{9}$. Os agricultores não perderam somente parte do seu território, mas também recursos vitais, principalmente áreas de veredas e brejos, justamente aquelas que produziam na estação seca a maior parte dos alimentos dos geralistas. ${ }^{10}$ Segundo Araújo (2010), com a maioria das terras férteis ocupadas pelas grandes empresas abaixo das nascentes, ou seja, a jusante dos cursos d'água, as populações rurais tradicionais ficaram a montante das nascentes, nas cabeceiras, terras de gerais, terras de solta, onde a maior parte dos solos são arenosos.

A SUDENE teve papel fundamental para a modernização dos gerais, proporcionado subsídios e incentivos fiscais para grandes projetos agropecuários, irrigação e reflorestamento. ${ }^{11}$ A população resistiu como pode à invasão destes empreendimentos nos gerais; a dificuldade, ou a enorme desvantagem, para organizar a resistência estava no apoio do Estado aos grandes grupos econômicos. Os geralistas estavam à mercê do poder transformador sem poder a quem recorrer.

A modernização no Vale do São Francisco sustentada pelo Estado através de programas e projetos afetou não só a segurança alimentar das famílias, mas também as relações econômicas entres povoados, comunidades e até mesmo o comércio das cidades. Os usos múltiplos dos microambientes dos gerais foram rompidos, e muitos agricultores ficaram restritos à vereda. Ribeiro (2010, p. 32) constatou que após a privação das famílias nas áreas comuns "apareceu uma nova população tradicional no Vale do São Francisco: o veredeiro, antigo lavrador de gerais, matas, veredas e brejos, a quem restou somente a vereda." $" 12$

Dentre as várias ações desenvolvimentistas implementadas nos gerais, o Programa Nacional de Várzeas Irrigáveis (PROVARZEAS) do governo federal, criado em 1975, teve resultados catastróficos para a região, que ficaram visíveis na natureza e enraizados na memória da população. Este programa afetou as bases da agricultura familiar geralista. Genelísio Marques de Deus (2010, p.212) descreveu como as lagoas marginais do rio São Francisco, berçários de peixes, foram drenadas para cultivos agrícolas, lagoas com mais de 100 hectares na bacia do rio Pandeiros; foram desmatadas vastas áreas para instalação de pivôs centrais de irrigação. $\mathrm{O}$ autor considera que um dos maiores desatinos do PROVARZEAS ocorreu na vereda do Pindaibal (em São Joaquim, distrito de Januária): “foram mais de 1.000 hectares drenados dessa vereda que desaguava 
no rio Pandeiros. Toda essa área foi drenada para plantar arroz e eucalipto, mas devido ao excesso de areia o eucalipto não vingou."

As empresas reflorestadoras foram responsáveis pelo assoreamento das nascentes e secamento de vários cursos de água, e agricultores familiares tiveram que mudar o manejo do gado, visto que as terras comuns destinadas às soltas foram cercadas e griladas. Agricultores dos gerais do rio dos Cochos relataram que foram "desmatados cerca de 10 mil hectares para a plantação de eucalipto. Não bastasse este, a primeira chuva que veio arrastou toda a terra para dentro da nascente do [córrego] Tatá" (SANTOS et al, 2010, p.186). A vegetação das encostas das chapadas servia de barreira natural para segurar a enxurrada de sedimentos que descia da parte de cima das chapadas. Com os desmatamentos das encostas, estes materiais foram transportados para os cursos d'água, e muitos destes foram soterrados e contaminados com os insumos utilizados nos eucaliptais (SANTOS et al, 2010).

As políticas voltadas para o Vale do São Francisco trouxeram graves consequências para a população dos gerais. Além de romperem com práticas tradicionais de convivência com a natureza, as políticas limitaram o acesso aos recursos naturais, atingindo a segurança alimentar e econômica destas famílias. Este quadro agravou-se ainda mais nos períodos de estiagem e seca prolongada, pois tornou necessárias ações de abastecimento de água para a população rural.

Desde o século XIX existem técnicas e programas públicos criados com o objetivo de suprir as demandas por água das populações do Semiárido. Por exemplo: cacimbas, cacimbões, barragens, depois caminhões-pipa, poços tubulares freáticos e artesianos, cisternas de uso doméstico e escolares. E, para produzir alimentos utilizando a água das chuvas, barragens subterrâneas, barragens de perenização, variedades vegetais adaptadas. Cada uma dessas iniciativas apresenta resultados diferentes, dependendo da população, de disponibilidade dos recursos hídricos, chuvas e meios de produzir alimentos e criar (SILVA, 2006; ARAÚJO et al, 2010).

Estas circunstâncias, aliadas aos períodos intermitentes de chuva, definem as condições de sobrevivência das comunidades rurais dos gerais. Toda a vida comunitária passou a se organizar em torno do acesso às fontes de água. Araújo et al (2010) calcularam que, no ano de 2007, existiam em Januária dez iniciativas governamentais e não governamentais para regularização do abastecimento de água. Eram projetos voltados 
para o combate e projetos de convivência com o Semiárido, sendo estas iniciativas classificadas em projetos e ações. Os projetos seriam as atividades planejadas, com objetivos traçados, tendo início meio e fim. As ações, seriam as práticas que não requeriam planejamento, sendo executadas de forma paliativa de acordo com a demanda existente. Araújo et al (2010) observaram que nenhum programa ou projeto de abastecimento de água foi implantado de forma independente: sempre necessitou da cooperação de outras instituições. Porém, havia um caráter centralizador em muitas destas iniciativas, e as populações beneficiadas tomavam conhecimento da proposta apenas quando estava sendo implantada, desconhecendo reivindicações e sugestões, com decisões passando por canais complexos que, na maioria das vezes, não estavam disponíveis para as comunidades rurais, centralizados em órgão executor, prefeitura, vereadores e deputados.

\section{Considerações finais}

Historicamente as secas fazem parte da história do Semiárido brasileiro. Foram relatadas por grandes autores, como Euclides da Cunha (1984) e Manoel Correia de Andrade (1980). Entretanto, a concentração fundiária desde o período da colonização agravou as consequências das secas, dificultando a vida no Semiárido. Não que tenham modificado o clima, mas a monopolização dos recursos naturais, principalmente terra e água, deixou à mercê da sorte a população, consequentemente contribuindo para agravar conflitos como retratou Facó (1963). A seca é um fenômeno natural, mas a concentração de terra e poder produz um conjunto de efeitos socioeconômicos que agudizam inclusive a escassez de água; a concentração da terra afeta a produção de alimentos e a dinâmica familiar.

As inúmeras iniciativas de regularização do abastecimento de água sem a participação popular, dificilmente se adaptam à realidade local das famílias de comunidades rurais do Semiárido, pois impedem a incorporação destas ações no cotidiano das pessoas. Esta dinâmica de abastecimento de água tende a resultados ineficientes, visto que a ausência de empoderamento destas pessoas no estabelecimento de regras, normas e articulações para lidar com este recurso torna-o escasso, apesar de ser primordial para a vida. 
Sendo assim, percebe-se que as descrições de convivência com os gerais relatadas por Galizoni (2005), Santos et al (2010) e Medeiros (2011) demonstram que não há uma população relacionada a apenas um determinado recurso natural do ambiente. As famílias de comunidades rurais vivem uma intensa dinâmica fluida com a natureza. Não eram só lavradores da mata, dos gerais, vazanteiros ou pecuaristas familiares. Estas, combinavam diversas técnicas para produzir alimentos, e os laços que uniram essa população com a natureza jamais poderão ser definidos numa única categoria - agricultura, apenas; ou pecuária, apenas - uma vez que há uso de amplo conjunto de conhecimentos para uso dos recursos da natureza.

\section{Notas}

\footnotetext{
${ }^{1}$ Neste texto será usada uma convenção: grafa-se Semiárido como maiúscula quando se refere à região, e semiárido com minúscula que se faz referência ao clima. Sobre as peculiaridades climáticas do Semiárido consultar Silva (2006) e Malvezzi (2007).

${ }^{2}$ http://www.integracao.gov.br/semiarido-brasileiro

${ }^{3}$ Para prever o tempo e as estações da chuva e conhecer o clima vindouro, as famílias de vazanteiros seguem uma profecia aprendida com os antigos, a "profecia dos olhos dos homens". Essa profecia "pode ser feita 'entre João e Pedro' (entre os dias de São João e São Pedro) iniciando no dia 24 de junho e terminando no dia 29 do mesmo mês: são seis dias e cada um corresponde a um mês: 24 equivale a julho, 25 a agosto, 26 a setembro, 27 a outubro, 28 a novembro e 29 a dezembro. Em cada um desses dias observa-se a formação do tempo; se durante o dia todo o céu carregar de nuvens como se fosse para chuva, significa que o mês correspondente a ele irá chover, se o dia passar inteiro aberto o sentido é que o mês correspondente será de sol, mas se o céu carregar de nuvens durante uma parte e abrir sol na outra parte, significa que metade do mês correspondente será de chuva e outra parte será de sol.” (GALIZONI, 2005 p. 131).

${ }^{4}$ Analisando outros "gerais", Carlos Dayrell estudou em Riacho dos Machados, área de altitude na transição entre os biomas Cerrado e Caatinga no Norte de Minas Gerais, e definiu como "gerais" aos planaltos, encostas de vales das áreas dominadas pelos cerrados, com solos normalmente ácidos e de baixa fertilidade natural (Dayrell, 1998, p. 73). Dayrell considerou que "a agricultura geraizeira, surgida de um mesclar de influências da agricultura indígena, colonial e negra, coevoluiu através dos séculos, possibilitando aos geraizeiros enfrentarem com criatividade as adversidades agroambientais dos gerais, nas regiões que fazem contato com a caatinga". (DAYRELL, 1998, p. 258).

${ }^{5}$ Sobre agricultura familiar e regimes agrários no Brasil consultar Martins (1981), Brandão (1981), Woortmann (1990), Wanderley (1996) e Herédia (2013).

${ }^{6} \mathrm{Em}$ algumas comunidades na área de transição entre gerais e mata o porte das árvores engana na hora de cultivar os mantimentos, pois árvores que indicam a fertilidade do solo podem ser encontradas em áreas de baixa fertilidade, sendo, portanto, o seu tamanho e vigor fatores pouco relevantes na hora de formar a lavoura.

${ }^{7}$ Ribeiro (2010), relata que os agricultores famílias dos gerais da margem esquerda do rio São Francisco se autodenominam como "geralistas". Já nos gerais da Serra Geral, segundo Dayrell (1998) os agricultores familiares se reconhecem como "geraizeiros". Este autor (p.21) escreveu que a "agricultura geraizeira" incorporou características do ambiente e uma forte influência de povos tradicionais: "Do mesclar destas diferentes influências no contexto da colonização, do isolamento das extensas regiões dos gerais, surgiu a agricultura geraizeira, onde não se pode negar a forte influência da agricultura indígena. Foi a partir deste
} 
mesclar, construído através dos séculos, que foi possibilitado aos geraizeiros enfrentarem com criatividade as adversidades agroambientais dos gerais, nas regiões que fazem contato com a catinga".

${ }^{8}$ Ribeiro (2010, p.27), escreveu que comunidades rurais "ficavam compreendidas numa grande área que os moradores mais antigos denominavam fazenda geral. A fazenda geral Mamede, a fazenda geral Maria Crioula; a Tejuco, Pandeiros, Macaúbas, Itapiraçaba; essas e muitas outras são as bases da divisão da área rural de Januária, Cônego Marinho e Bonito de Minas. Fazendas gerais, além de conter muitas áreas sem donos e outras dominadas por sítios e fazendas, reúnem logradouros - lugares determinados de pastejo em meio às chapadas de soltas -, veredas e capões, que são as áreas de terras mais férteis em meios aos chapadões de gerais."

9 Segundo Dayrell (1998, p.5) a modernização para o Norte de Minas "provocou um processo de miserabilização de suas populações, acentuando os desníveis socioeconômicos, a concentração das terras, associados com a degradação dos seus recursos naturais: solos, águas, flora e fauna."

${ }^{10}$ Nogueira (2009, p.63) estabelece que a "difusão do padrão monocultural reduziu a agrobiodiversidade local e restringiu sobremaneira o acesso aos recursos naturais, por parte das populações locais".

${ }^{11}$ Cardoso (2000, p.228) ressalta que "na medida em que grandes grupos econômicos ingressavam na região encontravam, muitas vezes, a resistência das populações ali estabelecidas. Devido ao cercamento de áreas comuns, utilizados para a solta e agroextrativismo".

${ }^{12}$ Ribeiro (2010, p.29), retrata que o "extraordinário estoque de recursos atraiu para a região interesses que provocaram um dos espetáculos mais brutais de destruição da natureza e da cultura material registrados nos tempos da revolução verde".

\section{Referências bibliográficas}

ANDRADE, M. C. Terra e homem no Nordeste. São Paulo. 1980.

ARAÚJO, V. M. RIBEIRO, E. M. REIS, R. P. Águas no rural do semiárido mineiro: uma análise das iniciativas para regularizar o abastecimento em Januária. Organizações Rurais \& Agroindustriais, vol. 12, núm. 2, 2010, pp. 219-233 Universidade Federal de Lavras - MG, Brasil.

BRANDÃO, C. R. O ardil da ordem: caminhos e armadilhas da educação popular. Campinas. 1983. Editora Papirus.

BRANDÃO, C. R. Plantar, colher, comer. Editora Grall LTDA. 1981. Rio de Janeiro.

CARDOSO, J. M. A. A Região Norte de Minas Gerais: Um estudo da dinâmica de suas transformações espaciais. In: OLIVEIRA, M. F. M. RODRIGUES, L. (Org). Formação social e econômica do Norte de Minas. Montes Claros. Ed. Unimontes. 2000.

COELHO, M. A. T. Os descaminhos do São Francisco. Editora Paz e Terra. São Paulo. 2005.

CUNHA, E. Os Sertões. São Paulo: Três, 1984 - Biblioteca do Estudante.

DAYRELL, C. A. Geraizeiros e biodiversidade no Norte de Minas: a contribuição da agroecologia e da etnoecologia nos estudos dos agroecossistemas tradicionais.

Dissertação (maestria) Universidade Internacional Andalucia. La Rábida, 1998. 
DEUS, G. M. In: RIBEIRO, E. M (org.). Histórias dos gerais. Belo Horizonte: Editora UFMG, 2010.

FACÓ, R. Cangaceiros e fanáticos: Gênese e Lutas. Editora UFRJ. 1963.

GALIZONI, F. M. Águas da vida: população rural, cultura e água em Minas Gerais Tese (doutorado) IFCH/Unicamp. Campinas, SP: 2005.

GERVAISE, Y. A transformação agrária do nordeste meridional (Norte de Minas Gerais). Belo Horizonte. UFMG / Instituto de Geociências / Departamento de Geografia, 1975.

HEREDIA, B. M. A. A morada da vida. Centro Edelstein de Pesquisas Sociais. Rio de Janeiro. 2013.

MALVEZZI, R. Semiárido: uma visão holística. Brasília: Confea, 2007, p.106.

MARTINS, J. S. Os camponeses e a política no Brasil. 1981. Rio de Janeiro.

MEDEIROS, C. P. No rastro de quem anda: comparações entre o tempo do Parque e o hoje em um assentamento no noroeste mineiro. Tese (doutorado) Museu Nacional / UFRJ. Rio de Janeiro, 2011.

MELLO, F.P. Os guerreiros do Sol: o banditismo no Nordeste brasileiro. Recife. Ed. Massagana. 1985.

NOGUEIRA, M. C. R. Gerais a dentro e a fora: identidade e territorialidade entre Geraizeiros do Norte de Minas Gerais. Tese (doutorado) UnB, Brasília - DF - 2009.

PEREIRA. A. E. Memorial Januária: terra, rios e gente. Belo Horizonte. Mazza Edições. 2004.

PORTO GONÇALVES, Carlos. Walter. As minas e os Gerais: Breve ensaio sobre o desenvolvimento e sustentabilidade a geografia de Norte de Minas. In: LUZ, Claudia; DAYRELL, Carlos (Org.). Cerrados e Desenvolvimento: tradição e atualidade. Montes Claros: CAA, 2000. p. 19-46.

QUEIROZ, M. I. P. O Mandonismo local na vida política brasileira e outros ensaios. São Paulo, Alfa-Ômega, 1976.

RIBEIRO, E. M. As histórias dos gerais. In: RIBEIRO, E. M (org). Histórias dos gerais. Belo Horizonte: Editora UFMG, 2010.

RIBEIRO, J. Folclore de Januária. Belo Horizonte. 2001. 
RODRIGUES, L. Formação econômica do Norte de Minas e o período recente. In: OLIVEIRA, M. F. M. RODRIGUES, L. (Ogr). Formação social e econômica do Norte de Minas. Montes Claros. Ed. Unimontes. 2000.

SANTOS, A. J. SOUZA, J. B. MATOS, J. G. R. PACHECO, J. M. S. VIANA, A. L. Terra, lavoura e criação no Rio dos Cochos. In: RIBEIRO, E. M (org). Histórias dos gerais. Belo Horizonte: Editora UFMG, 2010.

SILVA, R. M. A. Entre o combate à seca e a convivência com o Semiárido: transições paradigmáticas e sustentabilidade do desenvolvimento. Tese (doutorado) UnB, Brasília, 2006.

SPERA, S. T. REATTO, A. MARTINS, E. S. CORREIA, J. R. CUNHA, T. J. F. Solos areno-quartzosos no Cerrado: características, problemas e limitações ao uso. Planaltina: Embrapa Cerrados. ISSN 1517-5111, nº 7. p. 1-48. Dez 1999.

VIANA. J. F. In: RIBEIRO, E. M (org.). Histórias dos gerais. Belo Horizonte: Editora UFMG, 2010.

WANDERLEY, M. N. B. Raízes históricas do campesinato brasileiro. XX Encontro anual da ANPOCS. GT 17. Processos sociais agrários. Caxambu, MG. outubro 1996.

WOORTMANN, K. Com parente não se "neguceia": o campesinato como ordem moral. Anuário Antropológico/87. Editora Universidade de Brasília/Tempo Brasileiro, p. 11-73, 1990.

WOORTMANN, K. Migração, família e campesinato in Revista Brasileira de Estudos de População. Campinas, v. 7 nº1, p. 35-53, jan/jun 1990.

\section{Sites consultados}

Ministério da Integração Nacional. Semiárido Brasileiro. Brasília, 29/09/2017. Disponível em <http://www.integracao.gov.br/semiarido-brasileiro>. Acesso em 09/03/2018.

Portal do Sistema Nacional de Informações Florestais. Serviço Florestal Brasileiro. Disponível em: < snif.florestal.gov.br >. Acesso em: 05/07/2018. 